\title{
Baitul Mukarram: el islam en el espacio público del barrio de Lavapiés $^{1}$
}

Baitul Mukarram: Islam in the public space of Lavapiés

Óscar SALGUERO MONTAÑO

Universidad Complutense de Madrid

oscarsal@ucm.es

https://orcid.org/0000-0001-5289-1472

Recibido 19/6/2018.Revisado y aceptado para publicación: 16/11/2018

Para citar este artículo: Óscar SALGUERO MONTAÑO (2018), "Baitul Mukarram: el islam en el espacio público del barrio de Lavapiés" en Revista de Estudios Internacionales Mediterráneos, 25, 118-138.

Para acceder a este artículo: https://doi.org/10.15366/reim2018.25.007

\section{Resumen}

En nuestra actual sociedad aconfesional y plural los grupos religiosos comprenden el acceso al espacio público como un derecho a la ciudad. Este derecho legitima su estatus como actores sociales, diversos y sujetos de pleno derecho en la vida pública y responde, en aras de su reconocimiento e inclusión, a otras demandas sociales vinculadas a la modernidad y la transparencia. Para examinar esta hipótesis, mediante el estudio de caso de la comunidad musulmana bangladesí de Lavapiés, se analizan las circunstancias en las que los grupos religiosos tratan de acceder al espacio público, así como las prácticas y los discursos que despliegan durante sus actos y festividades en la vía pública en aras de obtener la mayor legitimación y reconocimiento posibles.

Palabras claves: Islam, Madrid, Lavapiés, espacio público, derecho a la ciudad.

\section{Abstract}

In our current nondenominational and plural society, religious groups understand access to public space as a right to the city. This right legitimizes their status as social actors, viewed as diverse and

\footnotetext{
${ }^{1}$ Este texto ha sido elaborado en el marco del proyecto CSO2015-66198-P «Expresiones Religiosas en el Espacio Urbano en Madrid y Barcelona (EREU - MyB)», Dirección General de Investigación Científica y Técnica y Subdirección General de Proyectos de Investigación del Ministerio de Economía y Competitividad, I+D+i Excelencia, convocatoria 2015.
} 
full subjects of law in public life, and responds -in the pursuit of its recognition and inclusion- to various social demands linked to notions of modernity and transparency. To explore this hypothesis, this article examines the case of Bangladeshi Muslims in Madrid's Lavapiés district. It analyzes the circumstances through which this community attempts to access the public space, and accounts for its different practices and discourses (displayed in specific events and festivities) in order to achieve further legitimization and recognition.

\section{Keywords:}

Islam, Madrid, Lavapiés, public space, right to the city.

\section{Introducción}

Las calles y plazas de nuestros pueblos y ciudades son el escenario cada vez más frecuentemente elegido por los fieles de las diversas confesiones, no sólo la católica, para la celebración de actividades de distinto tipo (cultuales, proselitistas, sociales y/o culturales), especialmente desde que el fenómeno del pluralismo religioso cuenta ya con la suficiente trayectoria como para que ahora sean también las minorías religiosas ${ }^{2}$ las que encuentren en el espacio público un escenario en el que desplegar sus estrategias de visibilización y repertorios de movilización. Las comunidades musulmanas son, en este sentido, unas de las más activas.

Son muchos los municipios del Estado español en los que, en grandes espacios al aire libre, o en amplios equipamientos comunitarios, se celebran los dos rezos colectivos más importantes del calendario islámico, el Eid al-Fitr a la finalización del Ramadán y el Eid al-Adha, o «fiesta del cordero». Ambas citas llegan a aglutinar en algunas ciudades como Madrid a miles de personas reunidas en parques, canchas deportivas o aparcamientos. Lo mismo sucede con los cristianos evangélicos, quienes en 2017 contaron con una gran presencialidad en el espacio público de muchos pueblos y ciudades con la conmemoración del 500 aniversario de la Reforma. Más que una conmemoración religiosa puede entenderse como'un «evento híbrido» en el sentido planteado por Michaela Pfedenahuer, demostrando las iglesias ser capaces «de responder de manera innovadora al desafío planteado por la pluralización», combinando elementos de los eventos modernos típicos de la cultura y de la sociedad actual, con otros de ceremonias tradicionales como los oficios religiosos (Pfedenahuer, 2010: 392). Los cristianos ortodoxos, por su parte, encabezados en número por la Iglesia Ortodoxa de Rumanía, desfilan cada año en muchos puntos de la geografía española durante la procesión nocturna de la Pascua portando velas encendidas en las inmediaciones de las parroquias ortodoxas. $Y$ lo mismo con tantas otras manifestaciones y tan dispares, y ya también cotidianas, como el Ratha Yatra que los Hare Krisna organizan anualmente por el centro de Madrid o el Khalsa de los sijs por las calles de Barcelona.

\footnotetext{
${ }^{2}$ El término «minorías religiosas» en el contexto político y social español comprende a todas aquellas confesiones reconocidas distintas a la Iglesia Católica, considerada la confesión históricamente mayoritaria de la sociedad española. Una y otras difieren en sus regímenes jurídicos de derechos y obligaciones, pero también en volumen de implantación social. Sobre el territorio pueden cartografiarse, según datos del informe Explotación de datos Directorio de lugares de culto -diciembre de 2017-, un total de 22.999 parroquias católicas en España. Entre las clasificadas como minorías se encuentran según la misma fuente 4.045 lugares de culto evangélicos, 1.569 musulmanes, 635 salones del reino de los testigos de Jehová, 196 iglesias ortodoxas (incluidas las orientales), 159 centros budistas, 117 mormones, 44 comunidades bahá'ís, 36 judías, 22 hindúes, 20 sijs, 15 puntos Scientology y 87 espacios más comprendidas como «otras» (Observatorio del Pluralismo Religioso en España, 2017: 3).
}

REIM № 25 (diciembre 2018) ISSN: $1887-4460$ 


\section{Pluralismo religioso, espacio público y derecho a la ciudad}

En el caso del islam, la demanda de visibilización en el espacio público, con el paso del tiempo y la consolidación de muchas comunidades, ha venido desplazando la que fue la principal necesidad de las comunidades que iban surgiendo al hilo de los flujos migratorios: la apertura de centros de culto islámico, tal y como demuestran las cifras del Registro de Entidades Religiosas, en el que durante la década de los 2000 se fueron inscribiendo un número cada vez mayor de oratorios y mezquitas para atender las necesidades de un colectivo mayoritariamente migrante (y marroquí) e integrado por familias que comenzaban a demandar una serie de servicios (educativos, sanitarios, y también religiosos). Si bien es cierto que actualmente el acceso a un lugar de culto acorde con las necesidades reales de muchas comunidades musulmanas sigue presentando una serie dificultades (como la falta de espacio en los oratorios y mezquitas para albergar al total de los fieles que asisten al salat de los viernes o a las festividades más significativas o la imposibilidad de obtener determinados permisos y licencias urbanísticas), en la presente década el ritmo de inscripciones musulmanas ha decrecido significativamente ${ }^{3}$, y son muchas también las comunidades que antes buscaban un sitio para responder a una de las primeras necesidades religiosas, el culto, y que ahora pretenden visibilizarse en la sociedad de la que forman parte ${ }^{4}$. Pretensión que da comienzo a una nueva etapa en el proceso de implantación, consolidación e institucionalización de las comunidades musulmanas ${ }^{5}$, en la que uno de los signos de legitimación social y reconocimiento institucional del pluralismo religioso «es la visibilización y apropiación del espacio público por parte de las otras religiones, tanto en sus manifestaciones proselitistas, como en sus celebraciones festivo-religiosas» (Salguero, 2010: 485). La visibilidad es, por tanto, parte de un proceso general de legitimación en el contexto urbano en el que se insertan los grupos religiosos, el cual puede cartografiarse sobre el territorio a través de las celebraciones religiosas, conmemoraciones y otros actos confesionales no cultuales realizados en la calle y en los equipamientos comunitarios públicos (Salguero, 2013: 418).

Si bien la ocupación del espacio público por las comunidades musulmanas sigue obedeciendo en muchos casos a la falta de espacio físico para albergar a grupos más o menos multitudinarios (Salguero, 2010: 485) y, en general, a una "precariedad endémica de recursos» (Alonso et al., 2010: 171), la visibilización comunitaria a través de esta diversidad de actos en el espacio público también responde en otros casos, como los de este estudio, a dos valores complementarios entre sí: la reivindicación de la diferencia y el derecho a la inclusión.

El énfasis en la diversidad se caracteriza por la reivindicación de lo distintivo y la búsqueda de una voz propia en la sociedad general, más en la línea de la «ciudadanía religiosa» expuesta por Wayne Hudson (2003), en virtud de la cual los marcos normativos y la propia institución de la ciudadanía necesitarán ser reconstituidos de acuerdo con los principios pluriconfesionales, además de seculares. A veces, esta estrategia consiste en el uso del espacio público para actividades confesionales como rituales y rezos colectivos; otras veces se expresa potenciando elementos distintivos (étnicos, nacionales, confesionales, denominacionales...) en la búsqueda del

\footnotetext{
${ }^{3}$ No así el de otras confesiones, que, por el contrario, han crecido significativamente, casos del cristianismo ortodoxo del Patriarcado de Rumanía y del budismo.

${ }^{4}$ Actualmente otras dos demandas de la comunidad musulmana en distintos puntos del Estado son contar con espacios funerarios acordes con las prescripciones islámicas y la enseñanza de religión islámica en los centros educativos públicos de enseñanza primaria y secundaria obligatoria y bachillerato, derechos reconocidos respectivamente en los apartados b) y c) del artículo 2 de la Ley Orgánica 7/1980, de 5 de julio, de Libertad Religiosa.

${ }^{5}$ Para una visión amplia del islam actual en España véase: Planet, Ana I. (ed.) (2019): Observing Islam in Spain. Contemporary Politics and Social Dinamics, Leiden, Brill.
} 
reconocimiento social de sus particularidades. Estos «rituales en la diáspora» de las comunidades musulmanas ponen en cuestión las teorías de la modernización más convencionales, que sugerían que la influencia secularizadora de la sociedad occidental llevaría a un progresivo abandono de estas ritualidades, mientras que el resultado ha sido que se trata de manifestaciones colectivas que las primeras generaciones de musulmanes han mantenido como recuerdo y refuerzo del vínculo con su país de origen, y que además son secundadas por las siguientes generaciones, tal y como plantean Alonso et al para el caso catalán (2010: 175).

El énfasis inclusivo, por su parte, utiliza recursos, demandas y representaciones socialmente hegemónicas que permiten escenificar la asunción por los grupos religiosos de los valores y preocupaciones compartidas por la sociedad general, facilitando un enmarcado para sus eventos que alude a la alineación entre las confesiones y la sociedad de la que forman parte. En otras ocasiones, el valor de inclusión podrá materializarse también en una mayor o menor invisibilización de la dimensión religiosa, en forma del "secularismo estratégico» que apunta Juan Marco Vaggione (2005) para referirse al desplazamiento en las argumentaciones religiosas como adaptación estratégica a nivel de las narrativas y las discursividades articuladas para defender determinadas concepciones generalmente más tradicionales.

Es decir, las manifestaciones en el espacio público de las comunidades musulmanas se conciben como una de las estrategias elegidas para «establecer una conexión relacional con esta sociedad, expresando una singularidad propia y, al mismo tiempo, su voluntad de formar parte de ella» (Alonso et al., 2010: 176).

Esta pretensión de visibilización se sustenta institucionalmente sobre la base del derecho fundamental a la libertad religiosa y de culto, que contempla el artículo 16.3 de la Constitución junto a la libertad ideológica. Para su materialización, además, los grupos religiosos en el actual contexto de "mercado religioso» altamente pluralizado (Berger, 1967; Luckman, 1967) entablarán con mayor o menor éxito múltiples procesos de negociación por la presencialidad y uso del espacio con distintos actores: las otras confesiones, la vecindad y los habitantes de la ciudad muchos de ellos fieles en potencia- y muy especialmente con los actores detentadores de la propiedad y la gestión del espacio urbano: los poderes públicos y los entes privados.

El espacio público, en tanto «espacio vivido» por la diversidad de los habitantes de la ciudad, se convierte así para las minorías religiosas en un «espacio de representación de lo imaginario y lo simbólico dentro de una existencia material» (Lefebvre, 2013: 16). La negociación con esos otros actores implica entonces acomodar el «espacio de representación» en el marco del "espacio concebido" por los gestores, técnicos, planificadores y expertos; en este caso, la Administración local y su gestión pública de la diversidad religiosa sobre el espacio de su jurisdicción. Pero también es concebido por actores privados con intereses especulativos sobre el suelo que determinan, en ocasiones, qué usos y prácticas del espacio público estarán o no permitidas en función de la imagen de marca que pretenda proyectarse del territorio. En este sentido, «el espacio concebido es, por tanto, el espacio de los signos, de los códigos de ordenación, de la fragmentación y la restricción» (Lefebvre, 2013: 16).

En este contexto, los grupos religiosos cuentan con espacios de proximidad, centrales y globales, en función de la localización espacial y de la audiencia a la que pretendan dirigirse. Los espacios de proximidad responden al entorno más cercano de la comunidad, generalmente las inmediaciones 
del lugar de culto, siendo sus destinatarios del entorno comunitario o próximo a este; los centrales, por su parte, se ubican en algún punto neurálgico de la vida comunitaria, como la plaza principal del barrio o junto a algún edificio institucional relevante, y las manifestaciones escenificadas en el mismo captan la atención de un público más amplio, religioso y también secular, generalmente el del barrio o zona en el que se desarrolle. Los espacios globales, por último, suelen traspasar las demarcaciones del barrio para ubicarse en el centro urbano, en algún punto especialmente referencial para el conjunto de la ciudadanía local. "Estar» en un espacio global pretende, por tanto, visibilizarse en un escenario supralocal, también estatal y, en ocasiones, internacional, global. La Puerta del Sol, en el distrito Centro de Madrid, es un claro ejemplo de este espacio global, además de ser, junto al barrio de Lavapiés, el enclave más multicultural de la ciudad (Peñalta, 2010: 111), en el que la reivindicación política y la protesta social han estado presentes durante prácticamente toda la historia democrática, con concentraciones de distinto color y signo o siendo el final de las manifestaciones que salían desde puntos como Cibeles o Atocha. El movimiento 15-M, por su parte, con la ocupación permanente entre el 15 de mayo y el 12 de junio de 2011, proyectaría este espacio a escala global, como punto de partida de una protesta ciudadana que se expandiría a muchos otros puntos del Estado y que tendría su correlato en otros países durante los meses siguientes.

No es de extrañar, por tanto, que un centenar de sijs, en septiembre de 2011, sin la presencia ya del $15 \mathrm{M}$, protagonizaran en este espacio global una concentración bajo el lema "No somos musulmanes. Tampoco somos talibanes. Somos sijs», tan solo unos días después de que un ciudadano norteamericano de esta confesión falleciese en una gasolinera de Arizona por los disparos de un pistolero que, por el turbante explicaría posteriormente, lo había confundido con un musulmán ${ }^{6}$. La protesta se desarrollaba, por tanto, en un contexto internacional marcado por los atentados autonodenominados "yihadistas» que estaban generando la multiplicación exponencial de ataques islamófobos contra personas musulmanas y sus espacios sociales y lugares de culto; y por el recrudecimiento en muchos países de las políticas y medidas securitarias. Los sijs reivindicaban de este modo el reconicimiento de la diferencia, tratando de aclarar cualguier confusión con un colectivo altamente estigmatizado como el musulmán; a la vez que se desmarcaban, en aras de su inclusión, de cualquier atisbo de extremismo mediante declaraciones como "Tampoco somos talibanes». Años después, en 2016, la Puerta del Sol volvería a acoger otra manifestación religiosa, esta vez de carácter muy distinto: los chiíes de Madrid elegirían este enclave durante el mes de Muharram, después de la Ashura, para montar un estand informativo en conmemoración del martirio del Imam Husain.

Esta reivindicación tanto de la diversidad, como del derecho a la inclusión de los grupos religiosos, convierten al espacio público también en espacio político para el ejercicio de los derechos cívicos y en espacio para la alteridad (Alguacil, 2008: 204), pues lo definitorio del espacio público es su tendencia "a la mezcla social», entendido como "un derecho ciudadano de primer orden», de modo que garantice «en términos de igualdad la apropiación por parte de diferentes colectivos sociales y culturales, de género y de edad" (Borja y Muxí, 2003: 11). El derecho a la inclusión en el espacio público forma parte, por tanto, del «derecho a la ciudad» (Lefebvre, 2017). Es un derecho fundamental en la ciudad porque es también donde se reconoce la diferencia, donde "se construyen la expresión e identificación social de los diversos» (Carrión, 2007: 84).

\footnotetext{
${ }^{6}$ El pistolero ejecutaría también el mismo día a un contable libanés en otra estación cercana y a una familia afgana en su domicilio.
} 
A partir de lo expuesto, el presente texto plantea la hipótesis según la cual en el contexto de una sociedad aconfesional y plural los grupos religiosos comprenden el acceso al espacio público como un derecho a la ciudad con el cual pueden legitimar ante la sociedad y las instituciones su estatus como actores sociales, diversos y sujetos de pleno derecho en la vida pública, a la vez que responder, en aras de su reconocimiento, a otros tipos de demandas sociales vinculadas a características como la modernidad o la transparencia. Para dar respuesta a este interrogante, este texto analiza las circunstancias en las que los grupos religiosos tratan de acceder al espacio público, así como conocer qué prácticas y discursos despliegan durante sus actos y festividades en el espacio público en aras de obtener la mayor legitimación y reconocimiento posibles. Para ello, se analizará el caso de la comunidad musulmana bangladesí de Lavapiés, la Comunidad Musulmana de Madrid Baitul Mukarram, y algunas de las actividades desarrolladas en el espacio público del barrio durante el 2017, prestando especial atención a las circunstancias en las que se desarrollaron y las pretensiones comunitarias sobre cada uno de los actos.

\section{Metodología}

Este estudio parte del acervo de haber estado inserto en una investigación de mayores dimensiones, desarrollada en las ciudades de Barcelona y Madrid e integrada por diversos casos correspondientes a distintas confesiones de una $y$ otra urbe entre un total de 41 investigadores/as.

En lo relativo a este estudio de caso, el colectivo bangladesí del barrio madrileño de Lavapiés conformado por alrededor de 2.500 personas, goza de gran visibilidad pública, cuenta con cierto tejido asociativo y empresarial y alberga en su seno una entidad islámica relevante y sujeto de este estudio, la Comunidad Musulmana de Madrid Baitul Mukarram, reconocida por los actores institucionales afectos y especialmente activa en el espacio público. Este perfil ha requerido un importante espacio para el trabajo etnográfico, que ha incluido la realización de una serie de entrevistas con informantes clave, seleccionados entre distintos actores: religiosos, de la propia comunidad, de otras comunidades vecinas musulmanas y también de otras confesiones; públicos, que han incluido a la concejalía del distrito y una técnica municipal; y asociativos, con el personal de una organización que trabaja con la comunidad bangladesí. También han surgido entrevistas informales que han aportado valiosa información con personal público participante en algunas de las actividades (policías, sanitarios y protección civil), vecinos y vecinas y comerciantes del barrio

Además, la presencia continuada en el espacio público a lo largo del año con diferentes actividades, ha traído consigo que las técnicas de observación hayan desempeñado igualmente un relevante papel, basculando entre la observación directa (caso de la oración de fin del Ramadán, donde el ritual fue recogido casi sin interacción con los fieles desde privilegiados puntos como muestra la Figura 3); y la participante (caso del iftar en el que el papel del investigador no diferiría notablemente del resto de asistentes), llegando en alguna ocasión por reciprocidad a desempeñarse otros roles distintos al observador (caso de las jornadas de puertas abiertas, en donde, a petición de los organizadores, se presentó públicamente la investigación tras las intervenciones de los representantes municipales, dotando así al acto de mayor institucionalidad, pues a la presencia del Ayuntamiento y de la Comisión Islámica de España, la CIE, se sumaba ahora la de la universidad). 
El contexto multicultural y plurirreligioso de Lavapiés en el que están presentes algunas de las confesiones más representativas del Estado, como son el catolicismo (que cuenta con dos populares parroquias), el cristianismo evangélico (con una significativa presencia gitana pentecostal, entre otras) y el islam, ha incidido igualmente sobre la metodología desarrollada. Ha sido pertinente acercarse no sólo a otras mezquitas, como Al-Huda, sino también a otras confesiones vecinas de Lavapiés, como la parroquia católica de San Millán, cuyo párroco está comprometido con el diálogo interreligioso y la integración social en el barrio. Para este otro apartado del trabajo de campo, de ejecución simultánea, se emplearon también las técnicas citadas; si bien, aspectos como la cercanía de la vecindad propiciaron, por ejemplo, que las observaciones a veces tan solo consistieran en un pausado paseo por las calles de un campo conocido, el del propio barrio del investigador, algo así como una deriva del flâneur, y a través del cual han podido registrarse situaciones y espacios no previstos en un primer momento. En este sentido, la investigación ha sido eminentemente adaptativa a las sucesivas circunstancias que han ido surgiendo durante el trabajo de campo.

En la base de la investigación también se han empleado una serie de fuentes de carácter documental, técnico y jurídico: fuentes estadísticas oficiales y algunas otras de organismos relacionados, como el Registro de Entidades Religiosas del Ministerio de Justicia o el Observatorio del Pluralismo Religioso en España, así como de las propias confesiones, como los informes anuales del Observatorio Andalusí, adscrito a la Unión de Comunidades Islámica de España (UCIDE); prensa online, que ha permitido contrastar algunos de los hechos pasados narrados durante las entrevistas y acercarse a los discursos institucionales de actores relevantes como el Ayuntamiento; legislación y normativa administrativa afecta, en sus niveles estatal, autonómico y local; y una serie de programas y planes de organismos públicos relacionados, como el borrador del Plan de Derechos Humanos (2017-2020) del Gobierno local.

\section{La vecindad bangladesí de Lavapiés}

La literatura española sobre la diáspora bangladesí y el papel en la misma de las comunidades islámicas es prácticamente inexistente, generalmente centrada en otros colectivos nacionales con mayor implantación y arraigo, caso especial de los marroquíes, junto a otros como pakistaníes o senegaleses. Es en el ámbito anglosajón donde los estudios sobre migrantes bangladesíes han proliferado, debido a que, en países como Gran Bretaña, este colectivo está asentado desde principios de los años setenta, contando con comunidades bastante numerosas. En este orden, son interesantes los trabajos de Eade y Garbin, D $(2002,2006)$ sobre la pugna entre seculares e islamistas por el liderazgo interno de la comunidad y las diferentes formas de entender el uso del espacio público londinense, y de Dench, Garvin y Young (2006) sobre la evolución sociocultural de la presencia migratoria bangladesí en barrios multiculturales de Londres como Brick Lane, en pleno corazón del East End.

Es también en un barrio multicultural, Embajadores-Lavapiés en el distrito Centro, donde reside la mayor parte de la población de origen bangladesí de la ciudad de Madrid, la cual, a 1 de enero de 2017, según cifras del INE, era de 4.981 personas censadas entre sus 21 distritos, concentrándose más de la mitad en el «popular» barrio de Lavapiés. A mediados de los noventa Lavapiés empezó a albergar a un importante número de población migrante no comunitaria, «hasta llegar a ser hoy día casi la mitad de la población del barrio» (Gómez, 2006: 1). 
La población bangladesí, o «bangla» como se autodenominaban a veces durante las entrevistas, está conformada en su mayoría por hombres jóvenes solos, que residen en domicilios compartidos con otros bangladesíes, o agrupados en familias jóvenes con hijos pequeños. Este colectivo no responde a un grupo cultural único, homogéneo; sus integrantes proceden de distintas provincias del país surasiático, como Sylhet, Faridpur, Narayanganj, Barisal o Chittagong, que sobre el tejido asociativo local se traducen en varias agrupaciones informales de carácter regional, pues las "distintas etnias y dialectos o giros dialécticos dentro del bengalí, que suponen rasgos muy característicos» son "uno de los factores que sirven para diferenciar a la población y saber su lugar de procedencia», tal y como se extrae del informe municipal del Centro Social Comunitario Casino de la Reina sobre este colectivo (Camacho, 2013: 5-6).

Existen también agrupaciones en lo relativo a la adscripción política, contando las principales fuerzas políticas de este país con alguna representación en el barrio: la Liga Awami de Banglades, actualmente en el gobierno; el Banglades Nacionalist Parti, en la oposición y cuyo presidente en España es a su vez el presidente de la mezquita; y el Jatiya Party, como alternativa a los dos grandes partidos citados (Camacho, 2013: 11-15). Todos y todas ellas, así como el resto de compatriotas residentes en España, en tanto migrantes, están representados por la Asociación de Bangladés en España con sede también en Lavapiés. Esta asociación dice no tener filiación política alguna, «aunque existe una lucha constante por obtener la presidencia de esta entidad, por la relevancia social que tiene dentro de la comunidad y el prestigio social que esto trae consigo» (Camacho, 2013: 9).

También han venido surgiendo otras organizaciones más reivindicativas, caso de la asociación Valiente Bangla, centrada en la lucha por los derechos de los migrantes y que reúne a no sólo miembros de esta procedencia. Pese a su carácter marcadamente secular, muchos de sus miembros son fieles activos de alguna de las comunidades musulmanas del barrio (como la bangladesí Baitul Mukarram o la senegalesa Al Taqua); además de colaborar puntualmente con la mezquita de Bangladés en la organización de algunas actividades, "hasta el punto de que las fronteras entre ellos son menos rígidas de lo que su discurso sugiere», tal y como afirman Eade y Garbin para el caso londinense al hilo de los debates entre bangladesíes secularistas e islamistas (2006: 91). La doble «militancia», religiosa y social, de algunos y algunas bangladesíes, sugiere adherirse al cuestionamiento de la tendencia de asociar "a las personas musulmanas con una lucha estructurada casi únicamente alrededor de la reclamación de derechos identitarios basados en la musulmaneidad», cuando la realidad es que su "conciencia de subalternidad no solo se estructura alrededor de una identidad religiosa no aceptada, sino también, y sobre todo, alrededor de una precariedad económica y laboral muy pertinaz en el caso de las poblaciones musulmanas» (Mijares y Lems, 2018: 126).

Para velar por los intereses de la clase empresarial bangladesí existe la Bussines Association Banglades, una patronal que «representa a todos los comerciantes que tienen algún negocio en nuestro país, aunque mayoritariamente están representados los que tienen un comercio en la zona de Lavapiés» (Camacho, 2013: 9). La sede de esta organización, en el número 26 de la calle Lavapiés, también alberga a la Asociación de Mujeres Progresistas de Banglades (o Banglades Progotishil Mohila Songstha), integrada por algunas de las esposas de los directivos de aquella y centrada en la atención e integración de las mujeres bangladesíes migrantes, muchas de ellas con un desconocimiento pleno del castellano, desempleadas y con escasa formación. 
La mayoría de los hombres y mujeres de este colectivo se adscribe confesionalmente al islam sunní, contando en el barrio con una importante comunidad musulmana de creyentes procedentes de este país o descendientes de estos. Gestada a lo largo de la primera década del milenio, se constituyó como entidad religiosa ante el Ministerio de Justicia en 2009 con el nombre de Comunidad Musulmana de Madrid Baitul Mukarram (en bengalí «la casa sagrada»), como la mezquita nacional de Bangladés, ubicada en su capital Daca. La comunidad reside en la mezquita Baitul Mukarram, más conocida como la «mezquita de Bangladés». Inaugurada antes de la propia constitución formal como entidad, en 2008 abría sus puertas en el número 9 de la calle Provisiones, siendo hasta el momento la más grande de las existentes en el barrio y que acoge a un mayor número de fieles, hasta 500 en el salat de los viernes, no sólo bangladesíes, pues a la misma también acuden, aunque en menor proporción, creyentes de otras nacionalidades.

En el seno del heterogéneo colectivo bangladesí islámico coexisten otras agrupaciones religiosas. Un caso es del Forum Islamic, integrado por unas 70 personas que se reúnen semanalmente en su sede del número 1 de la calle Provisiones, justo al lado de la mezquita, donde organizan actividades de formación y difusión en torno al islam y la cultura bangladesí (Camacho, 2013: 33). Otro caso es el de Banglades Anjumane-Al-Islah Spain, una organización no constituida formalmente en España y que responde a un movimiento internacional presente en aquellos lugares del mundo donde existen asentamientos bangladesíes significativos, como Madrid y Barcelona. Esta organización mantiene escasas relaciones con Baitul Mukarram y cuenta con una sede en un local bajo del número 14 de la calle Calatrava con la rúbrica de Hazrat Sahjalal Lotifia Cultural Center (Banglades), en la que se celebran los rezos diarios, se imparte formación y se organizan actividades, del mismo modo que en la de su homónimo barcelonés Centro Cultural Islámico Lotifia Fultoli Barcelona Spain, en el barrio del Raval.

Este significativo tejido asociativo, secular y religioso, responde a la dinámica general del propio barrio, el cual ha conservado en el imaginario su concepción como «espacio de protesta» y en el que actualmente existen numerosos movimientos, colectivos sociales y asociaciones (RodríguezBrochado, 2017: 126), muchas de las cuales están centradas en la defensa de los derechos de las personas migrantes, pero también del precariado, en las luchas vecinales contra la gentrificación y la especulación inmobiliaria, contra el racismo, contra la LGTIfobia, etc. Un contexto de diversidad que convierte a Lavapiés en un "ejemplo de tolerancia, pluralidad, diversidad y respeto", en el que desde los últimos años, con cinco lugares de culto islámico abiertos ${ }^{7}$, "la Navidad tiene menos eco que el Ramadán» (Caravaca: 2008: 24), llegando una conocida revista internacional de tendencias a dedicar un exotista artículo a la vecindad musulmana, en el que participaron, entre otros, varios entrevistados de Bangladés ${ }^{8}$.

En el orden institucional, Lavapiés ha recibido el reconocimiento de Distrito «libre de islamofobia», evento del que se dará cuenta posteriormente. También ha sido uno de los principales escenarios Las noches de Ramadán, un evento cultural promovido por el Ayuntamiento de Madrid, en

\footnotetext{
${ }^{7}$ En la trama urbana de Lavapiés, conformada por estrechas y agitadas calles, residen muchos otros musulmanes y musulmanas procedentes de diversos países, que también cuentan con mezquitas integradas por fieles de su misma procedencia, además de las dos citadas de población bangladesí: marroquíes en la primera mezquita de Lavapiés, AlHuda (1997) y durante un tiempo también en la Comunidad Musulmana del Centro de Madrid Ibad Al Rahmanen (2004), actualmente cerrada; pakistaníes en el Centro Religioso de Pakistaníes de España (2005); y senegaleses en la Comunidad Musulmana Senegalesa de Lavapiés Mezquita de Al Taqua (2011).

8 Bernal, Fernando, "Así viven los musulmanes del barrio de Lavapiés de Madrid», Vice, 31 de marzo de 2017, disponible en https://www.vice.com/es/article/kwj3gn/musulmanes-madrid-lavapies-3103 [consulta: 7 de junio de 2018]
} 
colaboración con Casa Árabe, y que en 2016 reuniría por vez primera una partida específica de 150.000 euros de los presupuestos municipales de 2016 para festejar el Ramadán. Este giro institucional de la Junta de distrito se enmarcaría en el Plan de Derechos Humanos del Ayuntamiento de Madrid (2017-2020), cuyo borrador por entonces contenía un total de 28 metas, cinco de las cuales -agrupadas en la Sección I- estaban destinadas a garantizar los Derechos Civiles y Políticos. En este conjunto, el Ayuntamiento incluyó la meta número tres, con la rúbrica de Derecho a la libertad de conciencia, religión, opinión e información. La primera medida en este ámbito que planteaba el borrador del Plan era la elaboración de un Protocolo de relaciones del Ayuntamiento y todas las confesiones religiosas que, «de conformidad con los estándares internacionales de derechos humanos, garantice el principio de no discriminación, su participación en la elaboración de políticas municipales que les afecten y su acceso a los servicios y equipamientos municipales sin discriminación»" ${ }^{9}$.

Es decir, el de Lavapiés en Madrid se trata de un espacio público más tolerante apoyado en el reconocimiento social e institucional que contrasta con otras realidades como, por ejemplo, la oposición vecinal a la apertura de mezquitas en puntos tan dispares como el barrio del Albaicín de Granada (Rosón, 2008), el centro en Premià de Mar y el de Singuerlín en Santa Coloma de Gramanet (Moreras, 2008) o el de Los Bermejales en Sevilla (Tarrés y Salguero, 2010).

Este contexto multicultural y aparentemente amable es atravesado actualmente por los efectos de un acelerado proceso de transformación urbana. Por un lado, persisten la marginalidad (Gómez, 2006: 3) y correlativamente, desde la Guerra Civil, la infravivienda (Pérez, 2009), además de otros fenómenos como la «hiper-presencia policial» y las «identificaciones preventivas» por criterios raciales (García-García, 2018: 8), la falta y deterioro de equipamientos comunitarios o las molestias por ruido y salubridad derivadas del creciente número de locales de ocio, que constituye por sí mismo otro de sus rasgos definitorios. Lavapiés está experimentando un importante proceso de terciarización, haciendo del sector servicios, hostelería y restauración, el principal reclamo turístico como motor productivo. Ámbito en el que, junto al comercio (fruterías, tiendas de alimentación y de artículos electrónicos), trabajan la mayor parte de los hombres de la vecindad bangladesí, caso de los restaurantes anunciados como «indios» o «hindúes»; sin obviar otras actividades de economía sumergida como la de los «lateros», que desempeñan jóvenes bangladesíes en las calles y plazas más transitadas. Una bolsa de trabajo precaria, similar al caso londinense, en donde pese a tratarse de un colectivo arraigado con jóvenes con educación superior, muchos de ellos «aún experimentan largos períodos de desempleo u ocupan puestos de baja calificación o no calificados al margen de la economía de servicios» (Eade y Garbin, 2002: 139).

Por otro lado, "el barrio está de moda», recientemente reconocido como el barrio más cool del mundo en el City Life Index de una revista internacional de ocio ${ }^{10}$, los imparables procesos de gentrificación y turistificación que está experimentando Lavapiés -y algunos otros barrios

\footnotetext{
${ }^{9}$ Otra actuación municipal en esta línea fue la declaración pública en marzo de 2016 de reservar una parcela de $10.000 \mathrm{~m}^{2}$ para la población musulmana en el cementerio de Carabanchel Alto, convirtiéndose en el futuro en el primer espacio funerario de la capital donde puedan enterrarse conforme a sus ritos religiosos.

${ }^{10}$ Bac, Marta, "Así viven los musulmanes del barrio de Lavapiés de Madrid», Time Out!, 18 de junio de 2018 , disponible en https://www.timeout.es/madrid/es/lavapies [consulta: 3 de octubre de 2018].
} 
limítrofes-está trayendo consigo que los precios de alquileres estén alcanzando niveles que dificultan enormemente el acceso a la vivienda de una serie de colectivos que cuentan con pocos ingresos, como el bangladesí. En este sentido, la comunidad londinense ya experimentó los efectos combinados de la gentrificación y la expansión de la ciudad hacia el barrio de Tower Hamlets, su principal asentamiento, produciendo cada vez más restricciones en sus oportunidades de acceder a una vivienda, mientras se alteraba el carácter local del barrio con la llegada de una "clase media blanca gentrificante» (Eade y Garbin, 2002: 138-139). Pese a esta amenaza, y al igual que en el caso británico, lo multicultural es marca Lavapiés, incorporándose incluso como reclamo turístico en los anuncios de plataformas como Airbnb, como si la impronta sobre el paisaje urbano de muchos de los colectivos migrantes vecinos del barrio, también la de los bangladesíes musulmanes, encajara estéticamente por alguna exotista razón y se convirtiera en ventaja competitiva de la marca Lavapiés como barrio multicultural.

\section{Baitul Mukarram en el espacio público de Lavapiés}

La significativa presencia del islam en Lavapiés se ha venido plasmando en su espacio público desde los dos últimos años con el aumento del número de actividades realizadas por algún colectivo islámico del barrio, reforzándose la visibilidad musulmana, y muy especialmente la del colectivo bangladesí, organizador de varias actividades inclusivas que, además, han contado la mayoría de las veces con el reconocimiento municipal de la Junta del distrito Centro, coincidiendo, como ha quedado expuesto, con el cambio de Gobierno local en las elecciones de 2015.

Para esta investigación se han tenido en cuenta una serie de eventos celebrados en 2017 por la Comunidad Musulmana de Madrid Baitul Mukarram, unos de carácter social y otros eminentemente confesionales. Entre los eventos sociales que se describirán a continuación se encuentran: una jornada de puertas abiertas con representación de las autoridades municipales y religiosas de la $\mathrm{CIE}$; la participación en un acto institucional de reconocimiento del distrito Centro «libre de islamofobia», junto a una delegación de representantes municipales y la celebración posterior de un iftar público en la mezquita; y una concentración contra los atentados autodenominados "yihadistas» de agosto en Barcelona y Cambrills. Entre los eventos confesionales, por su parte, ha sido seleccionada la oración del Eid al-Fitr, la fiesta de la ruptura del ayuno que trae la finalización del mes de Ramadán y que, junto al Eid al-Adha, constituye la cita cultual más importante del calendario islámico.

Jornada de puertas abiertas en la mezquita Baitul Mukarram, 13 de abril de 2017

Tenemos una sala muy grande, abierta, por eso tenemos bastante gente, puede haber 500 personas haciendo la oración. Ha ido cambiando: algunos imames que lo han hecho mal, se ha cambiado la Junta que tampoco funcionaba. La dirección nueva está funcionando bien. Si nosotros vivimos en un país abierto, también tenemos que abrir la ventana. Si la gente no abre la ventana, no pueden coger aire. Si en casa cerramos todas las puertas y ventanas es malo. Si abrimos las puertas, la gente conocerá a los musulmanes y sabrá cómo somos. Tenemos que compartir (miembro de Baitul Mukarram, Madrid, 4 de abril de 2017).

En 2017 las citadas actividades comenzaron en la mañana del sábado 13 de abril con una jornada de puertas abiertas en la mezquita a la que estaban invitados los representantes municipales y los responsables de los servicios sociales del distrito Centro, así como todo el vecindario, convocado mediante carteles en la calle, redes sociales y WhatsApp. Durante el acto se proyectaron diapositivas con textos (con alguna que otra falta de ortografía) sobre la cotidianidad de la 
mezquita, resaltando aspectos como las clases de árabe e islam para niños y niñas o la biblioteca de la segunda planta, además de algunas cuestiones básicas de la confesión, incidiendo en temas como el carácter pacífico del islam. Los contenidos del vídeo eran complementados con las aportaciones en perfecto castellano de una joven integrante de la comunidad y habitual interlocutora pública de la misma desde los últimos meses. Tras ello irían tomando la palabra distintas personalidades, desde Mohamed Ajana, secretario de la $\mathrm{CIE}$, el interlocutor oficial con el Gobierno español de las entidades musulmanas, e imam de la mezquita vecina de Al-Huda, hasta el concejal del distrito Centro, Jorge García Castaño, del grupo municipal Ahora Madrid, pasando por Carmen Cepeda, jefa de los Servicios Sociales del distrito. A la finalización del turno de palabras, el otro interlocutor habitual de la mezquita, presidente también de la asociación Valiente Bangla y conocido activista local por los derechos de las migrantes, aprovechó para comunicar públicamente en un complicado castellano ante las autoridades locales y la representación religiosa de la $\mathrm{CIE}$, por vez primera, la necesidad en el distrito Centro de contar con un centro cultural islámico y mezquita, al estilo de la mezquita Abu Bakr («Estrecho») y del Centro Cultural Islámico de Madrid («mezquita de la M-30»), apoyándose en el volumen y la diversidad de la población musulmana residente en el barrio de Embajadores-Lavapiés y en el carácter multicultural y plurireligioso de este. Días después, se comenzarían a ver en algunos comercios regentados por bangladesíes, como tiendas de alimentación, de artículos electrónicos o locutorios, las primeras huchas para recaudar fondos destinados a este propósito con la inscripción en castellano, árabe y bengalí: "Ayuda para el Centro Islámico Cultural Internacional de España», junto a un teléfono de contacto y la dirección de la mezquita Baitul Mukarram.

Acto público en la plaza de Lavapiés de reconocimiento del distrito Centro "libre de islamofobia", 30 de mayo de 2017

...en 25 años ningún político, ni el Ayuntamiento, han tenido un acercamiento. Somos una comunidad que llevamos 25 años y es muy numerosa, pero nunca han preguntado qué hacemos, qué necesidades tenemos, cómo estamos. Si tienes un vecino "¿Qué tal, como va tu vida?", pero nunca jamás ningún Ayuntamiento, ni concejal, ni la Comunidad [Autónoma], ni el Gobierno [central] se han interesado por la comunidad bangladesí. Es la primera vez (miembro de Baitul Mukarram, Madrid, 4 de abril de 2017).

Apenas un mes y medio después, recién comenzado el mes de Ramadán, en la tarde del martes 30 de mayo, nuevamente el concejal del distrito Centro y la jefa de Servicios Sociales, acompañados en esta ocasión del delegado de Salud, Seguridad y Emergencias del Ayuntamiento de Madrid, Javier Barbero, presidían en la plaza de Lavapiés, centro neurálgico del barrio, un acto en el que se presentaba públicamente el acuerdo aprobado por mayoría del Pleno municipal de la proposición de Ahora Madrid de reconocer al distrito centro "libre de islamofobia». Esta proposición, entre otras cuestiones, instaba a la dotación de competencias a la Unidad de Gestión de la Diversidad de la Policía Local de Madrid «para recoger denuncias ciudadanas especialmente relacionadas con la islamofobia».

El acto estuvo arropado por un mayoritario grupo de bangladesíes, integrantes de la comunidad de Baitul Mukarram, que portaban junto a varios representantes municipales una pancarta azul donde podía leerse en castellano y bengalí "Ramadán Mubarak», con la rúbrica de "LavapiésEmbajadores». Durante los 45 minutos del acto tomaron la palabra tanto las representaciones 
municipales, como los habituales interlocutores de la comunidad. Ante la prensa los representantes públicos afirmaron la intención de su grupo político de hacer de la lucha contra la islamofobia "una línea estratégica del Ayuntamiento de Madrid», además de poner en valor la labor de los Servicios Sociales del distrito «con una amplia población de todos los orígenes, en gran cantidad africanos y asiáticos que practican el islam». Los vecinos musulmanes, por su parte, destacaron el positivo acercamiento de la Junta de distrito a su comunidad, la necesidad de visibilizar un islam contrario a la oleada de atentados y, finalmente, reiterar la necesidad de contar en el distrito con un gran centro cultural islámico.

A la finalización del acto público, la comunidad bangladesí agradecía la invitación municipal con la celebración de un iftar, la ruptura del ayuno al caer sol, para los representantes municipales y el vecindario en general. Durante su transcurso, los dos mismos interlocutores de la cita anterior tomaron la palabra para explicar a los asistentes en qué consistía el Ramadán, junto a algunos aspectos básicos del islam, recordando nuevamente el total rechazo de la comunidad, y del islam en general, a la violencia. Sobre la jornada, el Ayuntamiento declararía al día siguiente en una nota de prensa, que este acto institucional tenía upor objeto mostrar el apoyo, reconocimiento y respeto del Ayuntamiento de Madrid a la comunidad musulmana, cada vez más numerosa, que reside en nuestra ciudad».

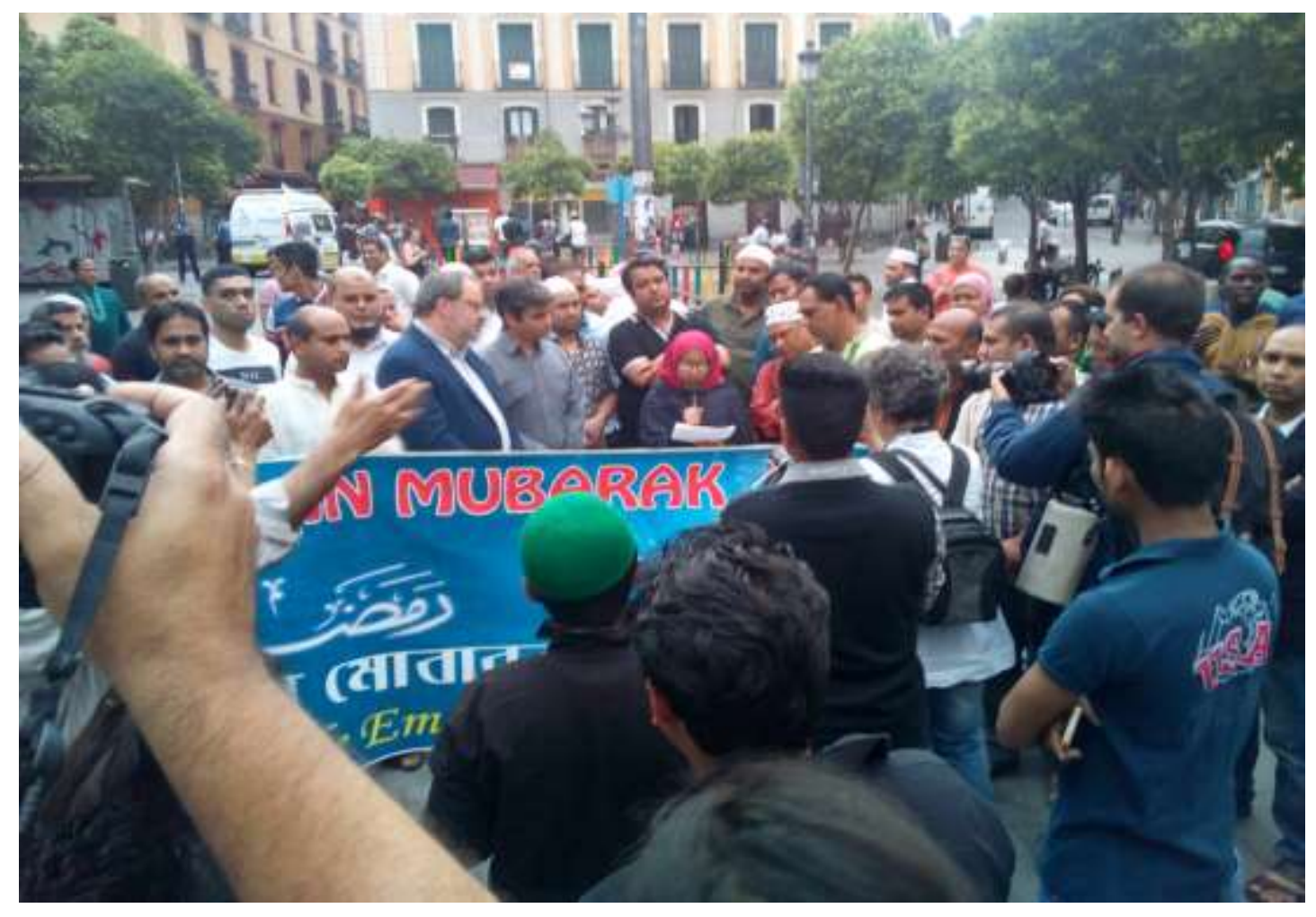

[Fig. 1] Los concejales Javier Barbero y Jorge García Castaño junto a miembros de Baitul Mukarram en el acto de reconocimiento del distrito Centro «libre de islamofobia» en la plaza de Lavapiés.

Foto: Ó. Salguero, 2017. 
El rezo colectivo del Eid al-Fitr en Lavapiés, 25 de junio de 2017 (30 de Ramadán de 1438)

...es un barrio donde vive mucha gente musulmana, más de 7.000 o 10.000 personas están viviendo aquí, el Ayuntamiento debería dejar algo fijo para que la gente musulmana haga su oración, porqué son dos fiestas muy importantes al año, no son dos fiestas normales, son fiestas muy importantes. Se pide a ellos [a la Junta de distrito] el permiso y también el equipo de sonido para que el imam pueda hacer la oración. No se cabe tampoco, unos tienen que estar por la mañana y otros una hora después porque no se cabe, porque hay más de 7.000 personas que están haciendo la oración (miembro de Baitul Mukarram, Madrid, 4 de abril de 2017).

Los rezos colectivos del Eid al-Fitr y el Eid al-Adha se vienen celebrando desde 2013 en las canchas deportivas al aire libre del Casino de la Reina, en la calle Embajadores esquina con Casino. Estas instalaciones son cedidas por el Ayuntamiento a la comunidad bangladesí, siendo este el colectivo mayoritariamente asistente, si bien, como en el caso de la oración de los viernes en su mezquita, también acuden muchos otros fieles de diversas nacionalidades, además de asistentes habituales a alguna de las otras mezquitas del barrio.

El domingo 25 de junio de 2017, a partir de las siete de la mañana, coincidiendo con la salida del sol, más de 6.000 personas -hombres y mujeres adultas, muchos jóvenes y niños y niñas pequeñas acompañadas de sus padres- ataviadas todas con sus mejores galas tradicionales, fueron llegando caminando hasta estas instalaciones para la celebración del Eid al-Fitr.

La oración fue oficiada por el imam de la mezquita Baitul Mukarram, también de Bangladés, y presidida en su comienzo por el concejal del distrito Centro quien, además de felicitar el Ramadán, afirmaría «estamos aquí para ayudar». Esta reiterada participación activa de representantes de la clase política en estas celebraciones ritualizadas, supone, como en el caso de Barcelona, "en sí mismo un hecho destacable, lleno de nuevos significados y de un intenso simbolismo" (Alonso et al., 2010: 175). Debido al volumen de asistencia se realizaron dos rezos consecutivos, uno de ocho a ocho y cuarenta y cinco y otro de nueve a nueve y cuarenta y cinco. La musala estaba dividida por sexos mediante una gran tela negra en el medio de la cancha, quedando las mujeres detrás y los hombres, muy superiores en número, delante y frente al imam. A los fieles orientados a la entrada principal de las pistas, en dirección a la Meca, tan sólo les separaba de la calle una traslúcida verja que permitía a los viandantes de la zona, mañaneros y trasnochadores, ver con todo lujo de detalles el transcurso de la celebración, convirtiéndose en una improvisada reivindicación de la diversidad. "Estamos rezando, no tenemos nada que ocultar», decían.

El acto transcurriría sin incidentes y en un ambiente de confraternización, especialmente a la finalización de cada uno de los rezos, pues en el parque anexo a las canchas y en las inmediaciones de la calle Embajadores se multiplicaban las felicitaciones y las invitaciones a casa, los apretones de manos y las buenas intenciones. 


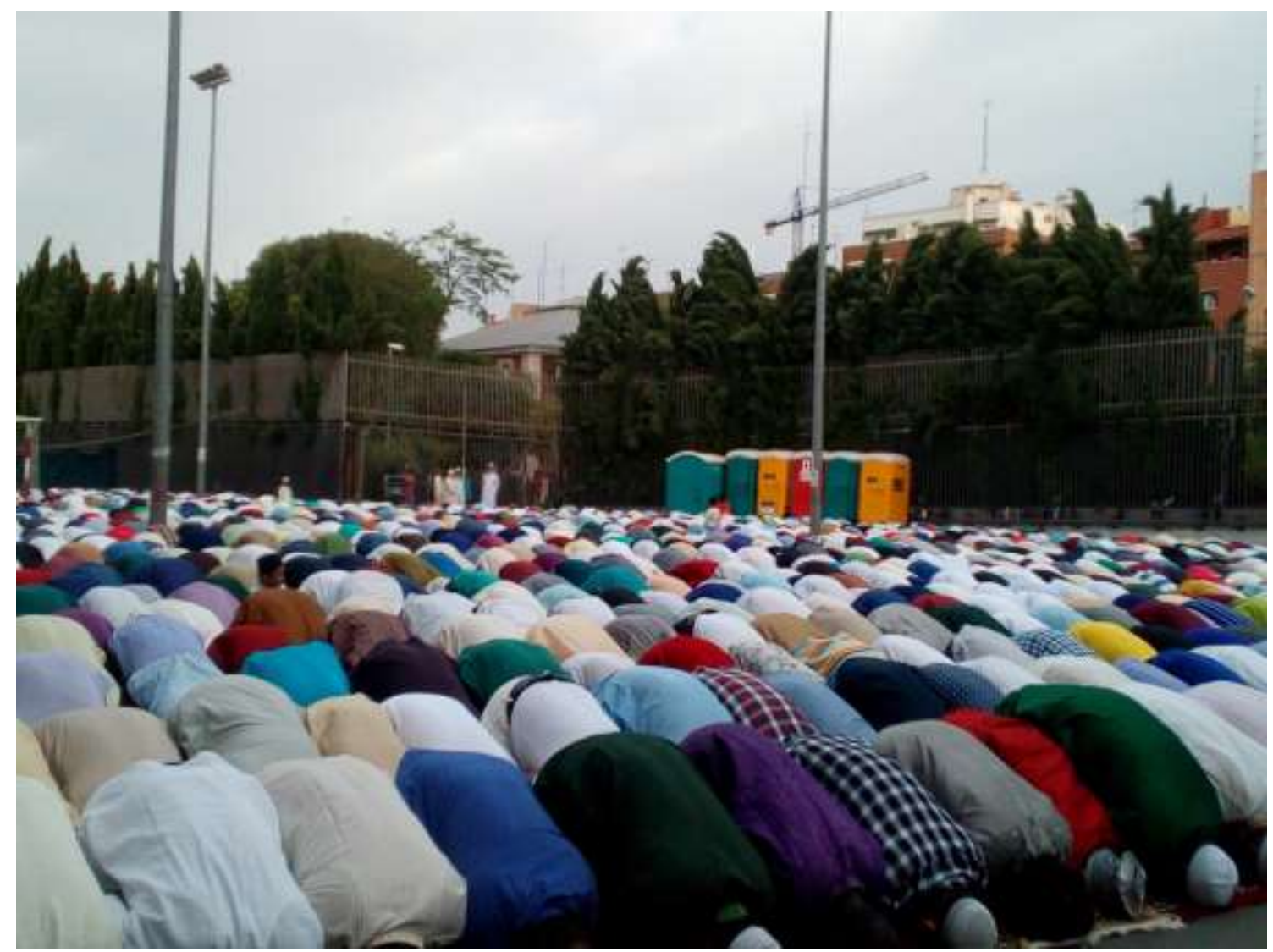

[Fig. 3] Fieles rezando durante el Eid al-Fitr celebrado en las canchas deportivas del Casino de la Reina en el barrio de Lavapiés.

Foto: Ó. Salguero, 2017.

Concentración en la plaza de Lavapiés de la comunidad musulmana bangladesí contra los atentados de Barcelona y Cambrills, 22 de septiembre de 2017

La gente dice que los musulmanes son terroristas, no somos terroristas. Si leen el Corán, si se sabe la historia, como los católicos, la historia de la religión, la Biblia y el Corán son casi iguales (miembro de Baitul Mukarram, Madrid, 4 de abril de 2017).

Otro evento no religioso en el espacio público de este barrio protagonizado por Baitul Mukarram fue una concentración también en la plaza Lavapiés contra los atentados autodenominados "yihadistas» de Barcelona y Cambrills del mes de agosto, convocada por la "Comunidad Musulmana de Madrid» (sin esta vez el epíteto Baitul Mukarram) bajo el lema "La Comunidad Musulmana de Madrid contra el terrorismo». Esta concentración, sin embargo, no contaría con las mismas facilidades organizativas que pudieron tener veces anteriores, pues una primera convocatoria anunciada por diferentes medios y prevista para las 15:15 horas del viernes 15 de septiembre, se vio suspendida in situ por un efectivo policial alegando que no habían solicitado autorización para su celebración, posponiendo una semana después a la misma hora y en el mismo sitio su correcto desarrollo.

La tarde del 22 de septiembre, después del salat al jumua del viernes, se concentraban nuevamente casi un centenar de vecinos musulmanes bangladesíes en la bulliciosa plaza de Lavapiés, ante las miradas de turistas con trolleys y de visitantes que empezaban a tomar las calles 
y ocupar las terrazas durante todo el fin de semana. Se repartieron pasquines nuevamente con la rúbrica de la Comunidad Musulmana de Madrid en los que podía leerse «¿Qué es lo que el islam dice del terrorismo?», pregunta a la que respondían con diversos versículos del Corán en los que se rechaza la violencia y con el lema "Amor para todos, odio para nadie». Muchos de los asistentes, en esta ocasión mayoritariamente hombres, portaban cartulinas de colores con lemas como «No en mi nombre», «El terrorismo no tiene religión» o «El islam busca la paz y el bienestar de toda la humanidad».

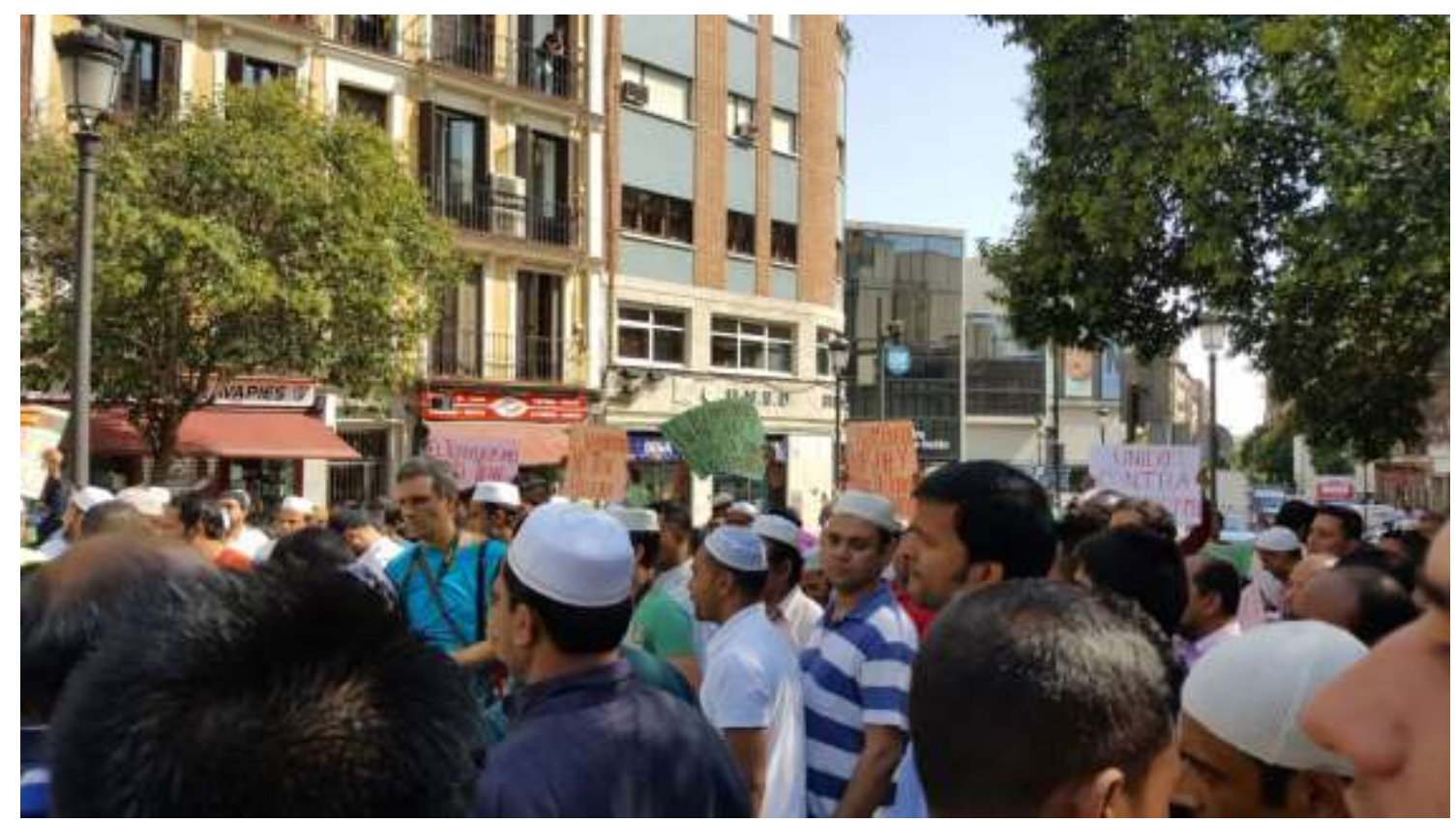

[Fig. 2] Algunos asistentes de la Comunidad Baitul Mukarram en el acto público contra los atentados de Cambrils y Barcelona, plaza de Lavapiés. Foto: A. Penas, 2017.

\section{Significados e implicaciones}

Este estudio da cuenta de la creciente visibilización de la comunidad islámica, especialmente la bangladesí, en el espacio público de Lavapiés, que responde, junto a la falta de espacios propios de estas dimensiones, a una doble pretensión: la reivindicación de la diferencia y el derecho a la inclusión. Una y otra están presentes en mayor o menor medida en cualquiera de los actos descritos. Si bien, la diferencia está manifiestamente presente en los grandes rituales religiosos colectivos y en actos como las puertas abiertas que potencian elementos etno-religiosos en la búsqueda del reconocimiento social de sus particularidades. La inclusiva, por su parte, se materializa claramente en eventos que remarcan la alineación entre la comunidad y la sociedad, en términos de modernidad y transparencia, casos del acto contra la islamofobia y la concentración contra el terrorismo. Por el contrario, no parece que Baitul Mukarram en aras de su inclusión invisibilice de algún modo su dimensión religiosa, como planteaba Vaggione (2005). 
En este marco los objetivos específicos planteados en 2017 por la comunidad a través de su visibilización pública han sido fundamentalmente tres: el ejercicio de rituales religiosos multitudinarios; la lucha contra el estigma y la islamofobia; $y$, ulteriormente, la colaboración política para la apertura de un gran centro cultural islámico.

En la base del primero de ellos se encuentran la representatividad real y simbólica de la vecindad musulmana y unos marcos gubernativo local y legislativo estatal que les legitiman para el uso del equipamiento comunitario, es decir, para ostentar el derecho de ciudadanía que incluye también el acceso libre, aunque fiscalizado, del espacio público en tanto espacio común para todos, y más especialmente la efectiva materialización del derecho fundamental de libertad religiosa y de culto. Las canchas municipales que sirven como musala ${ }^{11}$ suponen para la comunidad, por tanto, un espacio de proximidad (a escasa distancia de la mezquita), accesible y de legítimo uso; y también un espacio central, al tratarse punto referencial del islam local por la proximidad con el resto de mezquitas, por el uso cotidiano de jóvenes musulmanes y con carácter anual también por ser escenario de Las noches de Ramadán.

En lo relativo al segundo objetivo, la violencia autodenominada "yihadista», en conjunción con las "políticas securitarias amparadas en la garantía de la democracia y de las libertades sociales en el Estado español», han configurado "un nuevo sujeto sospechoso: "musulmán/a potencialmente terrorista"» (Téllez, 2018: 9). Ello sitúa también a la comunidad musulmana de Lavapiés en una condición de partida conflictiva basada en el estigma (quizás de menor intensidad que en otros barrios con menor presencia musulmana), y que por tanto es necesario contrarrestar desplegando determinadas estrategias de visibilización. Si bien este propósito quedó expresamente ejemplificado en el acto del mes de septiembre contra los atentados de Barcelona y Cambrills, hasta en el mismo Eid pueden encontrarse elementos que remiten al mismo. En este sentido, la participación al comienzo del evento del máximo representante del Ayuntamiento en el distrito implica también la moderna alineación de la política local con el proyecto comunitario; sin olvidar que la propia impronta generada en el paisaje urbano por este gran rezo colectivo a la vista de todos, supone también la transparente puesta en escena de un conjunto de elementos etnoreligiosos distintivos y definitorios de la comunidad, que ahora pueden observar también las gentes no musulmanas que habitan el espacio de proximidad del barrio.

El espacio público de Lavapiés, una vez apropiado simbólica y corporalmente por la comunidad musulmana bangladesí, ahora también con la legitimación institucional del Ayuntamiento, pasa a ser una tribuna desde donde demandar derechos de ciudadanía y plantear otras y nuevas necesidades, caso del tercer gran objetivo de Baitul Mukarram: la colaboración municipal en la construcción de un gran centro cultural islámico en el distrito Centro, que más allá del lugar de culto, se adecue a la actual realidad de un colectivo musulmán con más arraigo local y mayor visibilidad pública. Habrá que esperar, no obstante, si finalmente este gran centro cultural islámico se materializa en un barrio y en un distrito altamente turistificado y, en el caso de que así sea, cuáles serán las dinámicas vecinales que se generen en torno al mismo, que pueden ir desde su inclusión en el imaginario multicultural del barrio de Lavapiés, hasta su más frontal rechazo en forma de fenómeno nimby ${ }^{12}$.

\footnotetext{
${ }^{11}$ La musala es un espacio, generalmente al aire libre, sin cierres o tabiques, dedicado a oraciones de carácter ocasional, tales como las de algunas festividades, las fúnebres u otras.

${ }^{12}$ Acrónimo de la expresión inglesa Not In My Back Yard (no en mi patio trasero).
} 


\section{Conclusiones}

El espacio público, en tanto espacio para la alteridad, en el contexto del pluralismo religioso de las sociedades aconfesionales con libertad religiosa, es también el espacio de expresión e identificación social de la diversidad religiosa, donde se reconoce la diferencia interconviccional de la ciudadanía. La inclusión en el espacio público en términos de igualdad de las diversas confesiones constituye entonces un derecho de la ciudadanía, un derecho a la ciudad.

Un espacio público pretendido como un espacio social, de encuentro y también de conflicto, teniendo siempre en cuenta que dicha inclusión no sería posible sin la apropiación de un espacio físico, bien con carácter permanente en los casos de los lugares de culto y los espacios funerarios, o transitorio, efímero, cuando se trata del uso de espacios públicos, como las plazas de nuestras ciudades, para algún tipo de cita puntual y multitudinaria, religiosa o secular.

La creciente visibilización de Baitul Mukarram en el espacio público de Lavapiés está retroalimentada por un progresivo reconocimiento por parte de las instituciones públicas municipales al colectivo islámico bangladesí. En la alineación con la política local, la comunidad ha desplegado dos estrategias que destacan singularmente. En primer lugar, la adhesión a los repertorios de la modernidad mediante eventos seculares públicos, como la concentración contra los atentados, con pretensiones desestigmatizantes, en combinación con la puesta en valor de elementos propios religiosos, étnicos y nacionales, caso del iftar popular. Y, en segundo lugar, la proyección de una imagen de comunidad transparente ante la vecindad y el poder local mediante acciones como las jornadas de puertas abiertas o la celebración de sus dos grandes rezos colectivos en una cancha deportiva al aire libre.

Esta apertura responde también a un propósito desestigmatizante, lo cual no se contradice con que sea un barrio "multicultural y tolerante», se trata más bien un movimiento pendular en el que se desenvuelve el actor religioso y que va desde la ausencia de conflictividad en el espacio de proximidad, el propio barrio, comprendiendo el acceso al espacio público como una práctica del derecho a la ciudad que legitima su estatus de actores sociales, diversos y sujetos de pleno derecho en la vida pública (derecho a la inclusión y reivindicación de la diferencia); hasta la conflictividad en el espacio global basada en el estigma que sí plantea la necesidad de desplegar estrategias de visibilización y de responder, en aras de su reconocimiento, a otros tipos de demandas sociales vinculadas a características como la modernidad o la transparencia. Bajo estas premisas, la visibilización en el espacio público también podría comprenderse como otra exigencia securitaria y estigmatizadora que actualmente pesa tácitamente sobre el islam.

\section{Bibliografía}

ALGUACIL, Julio (2008): “Espacio público y espacio político. La ciudad como el lugar para las estrategias de participación", Revista Polis, no 7, 20, pp. 199-223.

ALONSO, Marta, GHALI, Khalid, LÓPEZ BARGADOS, Alberto, MORERAS, Jordi, SOLÉ, Ariadna (2010): "Rituals islàmics en diáspora: Les comunitats musulmanes a Catalunya", Revista d'etnologia de Catalunya, no 36, pp. 171-176. 
BERGER, Peter (1967): The Sacred Canopy: Elements of a Sociological Theory of Religion, Garden City, NY, Doubleday.

BORJA, Jordi y MUXÍ, Zayda (2003): El espacio público: ciudad y ciudadanía, Barcelona, Electa.

CAMACHO, Javier (2013): Resumen de las reuniones con los grupos de población Bangladesi de Lavapiés, Madrid, Centro Social Comunitario Casino de la Reina del Ayuntamiento de Madrid.

CARAVACA, Rubén (2008): "La España multicultural. Lavapiés, un mundo aparte”, Cambio 16, no 1894, marzo, pp. 24-25.

CARRIÓN, Fernando (2007): "Espacio público: punto de partida para la alteridad", en SEGOVIA, Olga (ed.): Espacios públicos y construcción social. Hacia un ejercicio de ciudadanía, Providencia, Ediciones Sur, pp. 79-97.

DENCH, Geoff, GAVRON, Kate y YOUNG, Michael (2006). The New East End: Kinship, Race and Conflict, Londres, Perfile Book.

EADE, John y GARBIN, David (2002): "Changing Narratives of Violence, Struggle and Resistance Bangladeshis and the Competition for Resources in the Global City", Oxford Development Studies, no 30, 2, pp. 137-149. https://doi.org/10.1080/13600810220138258

EADE, John y GARBIN, David (2006): "Competing visions of identity and space: Bangladeshi Muslims in Britain", Contemporary South Asia, no 15, 2, pp. 81-193. https://doi.org/10.1080/09584930600955291

GARCÍA-GARCÍA, Sergio (2014): “\#Policíasenacción. El Plan de Seguridad de Lavapiés", Contested_Cities. Working paper series, 14006, disponible en http://contested-cities.net/workingpapers/2014/policiasenaccion-el-plan-de-seguridad-de-lavapies/ [consulta: 3 de octubre de 2018] GÓMEZ, Mayte (2012): "El barrio de Lavapiés, laboratorio de interculturalidad", Dissidences. Hispanic Journal of Theory and Criticism, vol. 1, no 2, 12, pp. 1-42.

HUDSON, Wayne (2003): "Religious Citizenship", Australian Journal of Politics and History, no 49, 3, pp. 425-429.

LEFEBVRE, Henri (2013): La producción del espacio, Madrid, Capitán Swing.

LEFEBVRE, Henri (2017): El derecho a la ciudad, Madrid, Capitán Swing.

LUCKMANN Thomas (1967): The invisible religion: The problem of religion in modern society, New York, Macmillan.

MIJARES, Laura y LEMS, Johanna (2018): "Luchando contra la subalternidad: las reivindicaciones de la población musulmana en Madrid", Revista de Estudios Internacionales Mediterráneos, no 24, pp. 109-128. https://dx.doi.org/10.15366/reim2018.24.007

MORERAS, Jordi (2008): " "Hoy han hablado en la tele, de la mezquita del barrio». Los medios de comunicación en el contexto de los conflictos en torno a los oratorios musulmanes en Cataluña", en MARTíNEZ, María (ed.) Inmigración, discursos y medios de comunicación, Alicante, Instituto Alicantino de Cultura Juan Gil-Albert, pp. 127-142.

OBSERVATORIO DEL PLURALISMO RELIGIOSO EN ESPAÑA (2017): Explotación de datos Directorio de lugares de culto -diciembre de 2017-, Madrid, Fundación Pluralismo y Convivencia.

PEÑALTA, Rocío (2010): "Dos espacios multiculturales de Madrid: Lavapiés y la Puerta del Sol", Ángulo Recto: Revista de estudios sobre la ciudad como espacio plural, no 2, 2, pp. 111-117.

PÉREZ, Vicente (2009): Intervención y rehabilitación, 1998-2008, Madrid, Ayuntamiento de Madrid y Federación Regional de Asociaciones de Vecinos.

PFADENHAUER, Michaela (2010): "The eventization of faith as a marketing strategy: World Youth Day as an innovative response of the Catholic Church to pluralization", International Journal of Nonprofit and Voluntary Sector Marketing, n 15, 4, pp. 382-394.

PLANET, A. Isabel (ed.) (2018): Observing Islam in Spain. Contemporary Politics and Social Dinamics, Leiden, Brill. https://doi.org/10.1163/9789004364998 004 
RODRÍGUEZ-BROCHADO, Fernando (2017): “Resignificando la ciudad. Espacio público desde/para la ciudadanía en Esta es una Plaza de Lavapiés", Revista San Gregorio, no 17, enero-junio, pp. 118125.

ROSÓN, Javier (2008): ¿El retorno de Tarik? Comunidades etnorreligiosas en el Albayzín granadino (tesis doctoral), Granada, Universidad de Granada, disponible en http://digibug.ugr.es/handle/10481/1935 [consulta: 3 de octubre de 2018]

SALGUERO, Óscar (2010): "Necesidades de las comunidades religiosas en Andalucía”, en BRIONES, Rafael (dir.): ¿'Y tú (de) quién eres? Minorías religiosas en Andalucía, Barcelona, Icaria, pp. 481-492. SALGUERO, Óscar (2014): Espacio público y privado en el contexto del pluralismo religioso: minorías religiosas en Granada y su área metropolitana (tesis doctoral), Granada, Universidad de Granada, disponible en http://hdl.handle.net/10481/31206 [consulta: 3 de octubre de 2018].

TARRÉS, Sol y SALGUERO, Óscar (2010): “Musulmanes en Andalucía”, en BRIONES, Rafael (dir.): ¿Y tú (de) quién eres? Minorías religiosas en Andalucía, Barcelona, Icaria, pp. 289-377.

TÉLLEZ, Virtudes (2018): "El "Pacto Antiyihadista" y las estrategias de lucha contra la "radicalización violenta": implicaciones jurídicas, políticas y sociales", Revista de Estudios Internacionales Mediterráneos, no 24, pp. 9-30. https://doi.org/10.15366/reim2018.24.002

VAGGIONE, Juan Marco (2005): "Reactive Politicization and Religious Dissidence. The Political Mutations of the Religious in Social Theory and Practice", Social Theory and Practice, no 31, 2, pp. 233-255. https://doi.org/10.5840/soctheorpract200531210 